WellBeing International

WBI Studies Repository

3-1991

\title{
Discovery of Selected Water Dispensers by Newborn Pigs
}

P. A. Phillips

Agriculture Canada

D. Fraser

Agriculture Canada, dfraser@mail.ubc.ca

Follow this and additional works at: https://www.wellbeingintlstudiesrepository.org/houcfani

Part of the Agribusiness Commons, Animal Studies Commons, and the Operations and Supply Chain Management Commons

\section{Recommended Citation}

Phillips, P. A., \& Fraser, D. (1991). Discovery of selected water dispensers by newborn pigs. Canadian Journal of Animal Science, 71(1), 233-236.

This material is brought to you for free and open access by WellBeing International. It has been accepted for inclusion by an authorized administrator of the WBI Studies Repository. For more information, please contact wbisr-info@wellbeingintl.org.

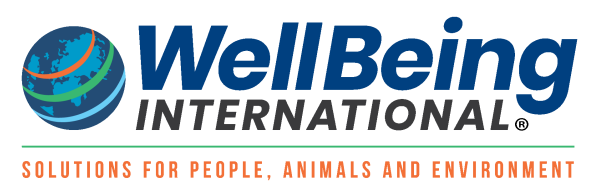




\title{
Discovery of Selected Water Dispensers by Newborn Pigs
}

\author{
P.A. Phillips and D. Fraser \\ Agriculture Canada
}

\begin{abstract}
KEYWORDS
piglet, water, dispenser design
\end{abstract}

\begin{abstract}
Newborn pigs in 86 litters were offered drinking water from four types of dispenser to determine how quickly each design would be discovered. On average piglets discovered water within about $24 \mathrm{~h}$ from an exposed water surface (bowl or cup), whereas discovery time was delayed to more than $72 \mathrm{~h}$ with nipple or push-lever dispensers. A prototype dispenser with a wide bowl and continuous bubbling action reduced $(P<0.05)$ average discovery time to about $14 \mathrm{~h}$.
\end{abstract}

Under certain conditions, dehydration may play a role in the early death of under-nourished piglets, and provision of supplemental water may improve survival rates (Fraser et al. 1990). However, little is known about designing water dispensers to encourage early discovery by newborn litters. Recent work has found that newborns are attracted to a water bowl equipped with a stream of bubbling air (Phillips and Fraser 1989). In addition, newborn litters consume more water from a larger bowl, sufficient to accommodate three piglets at once, which presumably allows piglets to learn to drink by imitating their litter-mates (Phillips and Fraser 1990). The purpose of this study was to determine the influence of dispenser design on the time required by newborn pigs to discover three selected commercial water dispensers and a prototype dispenser designed specifically to encourage rapid discovery.

Litters of newborn piglets were offered drinking water in one of five treatments (illustrated in Fig. 1): (1) The "nipple" treatment was a commercially-available stainless steel nipple dispenser intended for use with unweaned piglets (Model XYZ, Bauman Mfg., Wallenstein, ON). It was cylindrical and $10 \mathrm{~mm}$ in diameter, and it delivered water when a piglet displaced a lever protruding from the inside of the cylinder. (2) In the "push-lever" dispenser (Model 90, Suevia, Federal Republic of Germany) piglets pushed a vertical, 4-cmlong lever with their snouts to release water into a shallow, circular, cast-iron cup of $8 \mathrm{~cm}$ diameter, located below the lever. (3) The third treatment used the same "push-lever" dispenser, adjusted to give a continuous drip so that water was always available in the cup. (4) The "bowl" dispenser (Model No. 79, Nelson Products, Sioux Rapids, IA) had water continuously available in a plastic bowl, $110 \times 70 \times 22 \mathrm{~mm}$ automatically refilled by an attached, inverted 4-L canister. (5) The "prototype" dispenser was similar to the bowl dispenser' but included two features previously shown to encourage rapid discovery by young pigs (Phillips and Fraser 1989, 1990). First, water was provided in a longer semicircular trough that 
largely surrounded the canister. Second, two continuous streams of air caused a bubbling action at the water surface in two parts of the trough. The air was transferred from an aquarium pump through a 3-mm i.d. polyethylene to the two submerged outlets. Air flow rates of about $1700 \mathrm{~mL} \mathrm{~min}^{-1}$ per outlet were used.

In treatments 3, 4, and 5, the surface area of the water exposed to the piglets was approximately 50, 75 , and $300 \mathrm{~cm}^{2}$, respectively. All dispensers were mounted on the pen wall at the same location of the pen in an area accessible to the piglets but not to the sow. Except for the nipple, which was positioned $15 \mathrm{~cm}$ above the floor, the dispensers were placed at floor level.

Fig. 1. The types of water dispensers used in the study. A small set-screw near the top of the push-lever lever dispenser serves as the on-off control for the drip mode of operation.

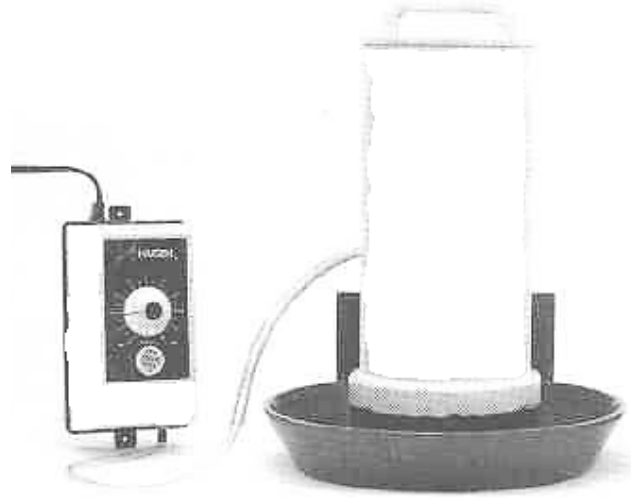

PROTOTYPE

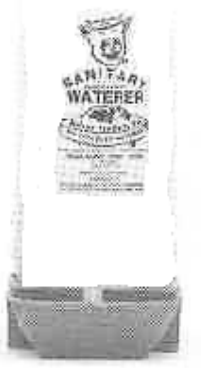

BOWL

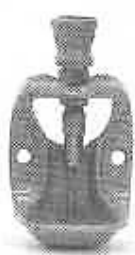

PUSH-LEVER

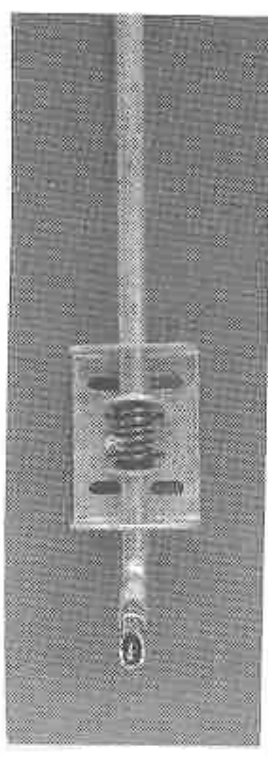

NIPPLE

The experiment involved 86 litters from the specific-pathogen-free Yorkshire and Land-race herd at the Animal Research Centre, Ottawa. The litters ranged from 8 to 15 pigs and averaged 10.2-10.9 for the various treatments. Average initial weights for each treatment ranged from 1372 to $1477 \mathrm{~g}$ and were within one standard error of the overall mean initial weight. Piglet mortality during the experiment averaged about 0.3 pig per litter and bore no noticeable relation to the treatments. A total of 33 litters were assigned to treatments 1,2 , and 3 . Since the differences among these treatments were obvious after relatively few litters had been observed, this pan of the experiment was ended when at least 10 litters had been assigned to each of the three treatments. The remaining 53 litters were assigned in an alternating manner to the bowl or prototype dispensers (treatments 4 and 5) in order to test whether the special features of the prototype would attract earlier use than the most similar commercially-available dispenser.

Sows were housed in temperature-controlled rooms $\left(23 \pm 4^{\circ} \mathrm{C}\right)$ in $0.6 \times 1.6-\mathrm{m}$ farrowing crates placed approximately in the centre of pens measuring about $2.1 \times 1.6 \mathrm{~m}$. Sows received water from a nipple drinker $0.6 \mathrm{~m}$ above the floor, well out of reach of the piglets. Pens had porous floors in the area of the sow's dispenser to ensure that water spilled by the sow would drain away rapidly and not be available to 
the piglets. Radiant heaters, suspended over $0.5 \mathrm{~m}^{2}$ rubber mats, were provided for piglet comfort and were located about $0.2 \mathrm{~m}$ from the water dispensers for all treatments.

Trials commenced between 08:00 and 10:00 $\mathrm{h}$ on the first morning after the litter was born. At this time (hour 0), piglets were weighed, marked with large ink numbers on their backs for identification, and provided with one dispenser. Piglet drinking behaviour was monitored by time-lapse video recording of closed circuit television images of the dispenser and surrounding area, recorded throughout the trial at one frame per $2 \mathrm{~s}$. The piglets were weighed again and re-marked after 24,48 and $72 \mathrm{~h}$, when the trial and video recording were stopped.

Water dispenser discovery time was determined from the video recordings for each member of a litter. For treatments 3, 4 and 5 where an exposed water surface was visible, mouth contact with the surface was the basis for recording frames in which water use occurred. For the push-lever dispenser (Treatment 2), use was recorded when a piglet's nose extended to the back of the bowl where the lever-valve was located. For the nipple dispenser (treatment 1), use was recorded if the piglet's mouth was positioned over the end of the nipple. An hourly log was kept of each video frame in which u piglet met these conditions until a total of 10 frames (corresponding to $20 \mathrm{~s}$ of dispenser use) had been observed for each individual. Observations on that piglet were then discontinued. Tape review was continued until the end of the trial $(72 \mathrm{~h})$ or until all individuals had logged 10 frames of dispenser use. Data were ignored for 27 piglets which died during the trial.

Table 1. Mean body weight gain and median hours taken by piglets to discover water dispensers

\begin{tabular}{|c|c|c|c|c|}
\hline \multirow[b]{2}{*}{ Dispenser type } & \multirow[b]{2}{*}{ No. of litters } & \multirow[b]{2}{*}{$\begin{array}{l}\text { Mean body wt. gain } \\
\left(\mathrm{g} \mathrm{d}^{-1}( \pm \text { SEM })\right)\end{array}$} & \multicolumn{2}{|c|}{ Median hours to discover dispenser ${ }^{z}$} \\
\hline & & & 2-frame criterion & 10-frame criterion \\
\hline Nipple & 10 & $118 \pm 12$ & $>72 a[55->72]$ & $>72 d^{y}$ \\
\hline Push-lever, no drip & 10 & $116 \pm 8$ & $>72 a[55->72]$ & $>72 d^{\mathrm{y}}$ \\
\hline Push-lever, with drip & 13 & $102 \pm 9$ & $19 b[5-54]$ & $23 e[8->72]$ \\
\hline Bowl & 28 & $124 \pm 6$ & $14 b[3-54]$ & $25 e[8-66]$ \\
\hline Prototype & 25 & $122 \pm 7$ & $5 c[2-33]$ & $14 f[5-51]$ \\
\hline
\end{tabular}

${ }^{\mathrm{z}}$ Median and range of each litter's discovery time.

${ }^{y}$ No litters met this criterion.

$\alpha-f$ Medians with different letters are significantly different $(\alpha, b ; \alpha, c ; d, e ;$ and $d, f: P<0.01 ; b, c: P<0.05 ; e, f: P<$ 0.02 ) by the median test.

Each litter's "discovery time" was expressed as the median of the time taken by the individual litter-mates to reach criteria of either 2 or 10 frames at the dispenser. Two criteria were used to ensure that the somewhat arbitrary choice of criterion would not have undue influence on the comparison. The overall comparison of treatments was done by the extension of the median test, and pairwise comparison of treatments was by the median test (Siegel.1956).

Litter-weight gains averaged 78, 122, and $148 \mathrm{~g} \mathrm{~d}^{-1}$ on days 1,2 , and 3, respectively, and the mean daily weight gain for each treatment was within one standard error of these means (Table 1). Six-litters lost weight on Day 1, but by Day 2, all were gaining weight.

Discovery times differed greatly between dispenser types, and the two different criteria for discovery (2 or 10 frames at the dispenser) had almost no influence on the relative ranking of the dispensers (Table 1). The nipple and push-lever dispenser without continuous drip, both of which required the piglet to actuate the valve to get water, took a median of over $3 \mathrm{~d}$ to discover. Where water was visible in the dispenser 
(bowl, prototype, and push-lever with drip) discovery time was reduced considerably to about $1 \mathrm{~d}$ or less. Discovery times were significantly shorter for the prototype than for the bowl $(P<0.05)$ or other dispensers.

In this study the two types of water dispenser which had to be valve-actuated by the piglets were not discovered and used by most animals in the first $3 \mathrm{~d}$ after birth. Most piglet deaths occur within these $3 \mathrm{~d}$ (English et al. 1977). If dehydration contributes to these deaths, then valve-actuated water dispensers of the designs tested are unlikely to rectify the problem because of the long time required for piglets to discover them.

Median discovery times were reduced considerably, to about $1 \mathrm{~d}$ or less, using a bowl or cup where the water was exposed. Bowl designs seem to offer the most promise although care must be taken to ensure that the contents are kept clean (Brooks and Carpenter 1990). This can be achieved by the continuous flow of water into the dispenser (e.g., the push-lever dispenser with drip) but continuous flow uses larger volumes of water and creates additional waste which must be stored and disposed of.

Building on previous work, the prototype dispenser was designed specifically to encourage early discovery by piglets. (See Lewis and Hurnik (1979) for a similar approach in designing a feed dispenser for turkey poults.) The litter is a social group which tends to feed, play, and drink in short bouts of activity. The circular bowl accommodates the natural synchrony in piglet behavior as it allows piglets to use the dispenser by imitation (Phillips and Fraser 1990). The prototype dispenser also used bubbling sounds and water movement in the bowl to draw piglet attention (Phillips and Fraser 1989). These features brought about a significant reduction in discovery time compared to the other treatments and demonstrate that there could be room for improvement in commercial dispenser designs.

This study focused on dispensing water, but there is increasing interest in dispensing liquid nutrient supplements to newborn piglets. Such supplements must be discovered and consumed as early after birth as possible. The findings from this work could be applicable to the development of this type of equipment.

\section{ACKNOWLEDGEMENTS}

The authors wish to acknowledge the skillful assistance of D. Alves and S. Fournier in conducting the trials and J. M. Leclerc and the ARC shop in fabricating the prototype water dispenser.

\section{REFERENCES}

Brooks, P. H. and Carpenter, J. L. 1990. The water requirement of growing-finishing pigs--theoretical and practical considerations. Pages 115-136 in W. Haresign and D. J. A. Cole, eds. Recent advances in animal nutrition. Butterworths, London, U.K.

English, P. R., Smith, W. J. and MacLean, A. 1977. The sow, improving her efficiency. Farming Press Limited, Ipswich, U.K.

Fraser, D., Patience, J. F., Phillips, P. A. and McLeese, J. M. 1990. Water for piglets and lactating sows: quantity, quality and quandaries. Pages 137-160 in W. Haresign and D. J. A. Cole, eds. Recent advances in animal nutrition. Butterworths, London, U.K.

Lewis, N. J. and Hurnik, J. F. 1979. Stimulation of feeding in neonatal turkeys by flashing lights. Appl. Anim. Ethol. 5: 161-171. 
Phillips, P. A. and Fraser, D. 1989. A water dispenser modified to promote water use by piglets in the first days after birth. Can. Agr. Eng. 31: 175-177.

Phillips, P. A. and Fraser, D. 1990. Water bowl size for newborn pigs. Appl. Eng. Agric. 6: 79-81.

Siegel, S. 1956. Nonparametric statistics for the behavioral sciences. McGraw-Hill Book Co., Toronto, ON. 